\title{
POLÍTICAS EDUCACIONAIS, VISÕES DE MUNDO E A ARTICULAÇÃO EM PROCESSOS EDUCATIVOS
}

\author{
Educational policies, world views \\ and the articulation in educative processes
}

\author{
Noemi Boer ${ }^{1}$ \\ Edmundo Carlos de Moraes ${ }^{2}$
}

Resumo: O trabalho teve como foco a discussão das políticas educacionais em educação ambiental e as visões de mundo com a finalidade de explicitar as implicações dessas em processos educativos. As visões de mundo são concebidas como macroestruturas epistemológicas, que compreendem um conjunto de valores, crenças, conceitos e formas de conhecimento que fundamentam as concepções e ações educativas. $\mathrm{O}$ trabalho apresenta, também, os componentes das visões de mundo e a maneira como esses se articulam em processos educativos. Esse aspecto é importante para se poder identificar as concepções de mundo subjacentes às práticas pedagógicas desenvolvidas pelas escolas. $\mathrm{Na}$ visão integrada de mundo, a problemática ambiental é entendida como decorrente do modelo de desenvolvimento social e das relações que os seres humanos estabelecem entre si e com o ambiente não humano. Considera-se, ainda, que a perspectiva relacional pode contribuir para uma mudança na atual abordagem da Educação Ambiental.

Palavras-chave: políticas educacionais. educação ambiental. visões de mundo.

\begin{abstract}
This paper focuses on the discussion of educational policies in environmental education and on world views, for the purpose of clarifying their implications in educative process. The world views are conceived as epistemological macro-structures which consist of a set of values, beliefs, concepts and forms of knowledge which are the base for conceptions and educative actions. The paper also presents the components of the world views and the ways in which these components are articulated in educative processes. This aspect is important in order that the world conceptions underlying pedagogical practices developed by the schools may be identified. In an integrated world view, an environmental issue is conceived as a relational issue resulting from the model of social development and the relationship which the human beings establish among themselves and with the non-human environment. It is considered that the relational perspective may contribute to a change in the current approach of the environmental education.
\end{abstract}

Key words: educational policies. world views. educative processes.

\footnotetext{
${ }^{1}$ Doutoranda, Programa de Pós-Graduação em Educação Científica e Tecnológica, Universidade Federal de Santa Catarina; Docente, Centro Universitário Fransciscano, Santa Maria, RS.E-mail:nboer@terra.com.br

${ }^{2}$ Laboratório de Pesquisa para um Conhecimento Integrado, Departamento de Ecologia e Zoologia, Centro de Ciências Biológicas, Universidade Federal de Santa Catarina, Florianópolis, SC. E-mail: laborpeci@ccb.ufsc.br
} 
Boer, N.; Moraes, E. C.

\section{Introdução}

As atuais políticas educacionais brasileiras têm como pano de fundo o contexto econômico, político e social vivido na década de 1980. No plano econômico, essa década foi considerada pelos economistas como a "década perdida". Na esfera política, dá-se a redemocratização da sociedade brasileira ao se completar o processo de transição do governo militar para o governo civil, com o restabelecimento das eleições diretas. Na esfera social, ocorre a reorganização dos movimentos sociais e a criação de inúmeras entidades de classe e instituições. Outro aspecto importante foi o processo constituinte que gerou a Constituição Federal de 1988. Desse contexto e das discussões realizadas no final da década de 1980 e início da década de 1990, definiram-se as atuais políticas educacionais (Arelaro, 2000). A implantação dessas políticas, na década de 1990, gerou uma verdadeira reforma tanto na Educação Básica quanto no ensino superior.

Os principais documentos que estabelecem as atuais políticas educacionais para a Educação Básica do país são os Parâmetros Curriculares Nacionais (PCNs), fundamentados na Lei de Diretrizes e Bases da Educação Nacional, Lei no 9.394/96, e as Diretrizes Curriculares Nacionais. No entanto, a justificativa para a elaboração dos PCNs baseou-se no Artigo 210, da Constituição de 1988, que determina como dever do Estado fixar conteúdos mínimos para o Ensino Fundamental, tendo em vista assegurar a formação básica comum e respeito aos valores culturais e artísticos, nacionais e regionais. Fundamentaram-se, também, no Plano Decenal de Educação para Todos (1993 - 2003), que destaca a necessidade do aumento da qualidade da Educação Fundamental e a articulação de esforços para a reformulação curricular desenvolvida pelos Estados e Municípios (Bonamino e Martínez, 2002).

Quanto às discussões internacionais sobre a Educação Ambiental, nesse período, estas já estavam consolidadas em diversos países, sobretudo, nos europeus. No Brasil, eram tomadas as primeiras iniciativas oficiais para se implantar a Educação Ambiental escolar. Assim, as principais políticas públicas para a Educação Ambiental foram definidas a partir da Constituição Federal, de 1988, que estabeleceu, no capítulo sobre o meio ambiente, a Educação Ambiental como direito de todos e dever do Estado. Em 1994, os Ministérios da Educação (MEC) e do Meio Ambiente (MMA) criam o Programa Nacional de Educação Ambiental (Pronea). Entretanto, a consolidação da Educação Ambiental escolar se efetivou basicamente a partir das orientações dos Parâmetros Curriculares Nacionais - Tema Transversal Meio Ambiente, de 1998. Em 1999, foi aprovada a Política Nacional de Educação Ambiental - Lei 9.795, regulamentada em 2002. Nesse mesmo ano, o MEC fez a implementação do Programa Parâmetros em Ação: meio ambiente na escola; e, em 2003, foi criado o Órgão Gestor da Política Nacional de Educação Ambiental pelo MEC e MMA (Carvalho, 2004). Por isso, o propósito, neste trabalho, é analisar as possíveis articulações da Educação Ambiental nos processos educativos, com base nas políticas educacionais e nas visões de mundo.

\section{As políticas educacionais atuais e a Educação Ambiental}

Neste estudo, considera-se importante focar a análise nos PCNs, dada a repercussão desses documentos nas diferentes esferas educacionais e, de forma particular, na Educação 
Ambiental escolar. Os parâmetros propõem uma educação comprometida com a cidadania, apontam para a necessidade de se resgatarem os princípios de convivência, baseados na liberdade, no diálogo e na responsabilidade. Elegeram, assim, trabalhar quatro pontos básicos: a dignidade da pessoa humana, a igualdade de direito, a participação e a co-responsabilidade pela vida social e coletiva (Brasil, 1998).

A versão final dos Parâmetros Curriculares Nacionais para a $1^{a}$ a $4^{a}$ séries foi apresentada pelo Ministério da Educação e do Desporto, em 1997, e a versão final para o ensino de $5^{a}$ a 8 a séries, em 1998. O volume que apresenta os Temas Transversais trata de questões sociais referentes à Ética, Saúde, Orientação Sexual, Meio Ambiente, Trabalho e Consumo e Pluralidade Cultural. Para eleger os Temas Transversais, foram quatro os critérios adotados: urgência social, abrangência nacional, possibilidade de ensino e aprendizagem no Ensino Fundamental e, por último, a compreensão da realidade e da participação social (Brasil, 1998).

Os PCNs apresentam o meio ambiente como um dos Temas Transversais, cujos conteúdos devem ser trabalhados pela Educação Ambiental, de forma sistemática, abrangente, interdisciplinar e transversal nas disciplinas. Os objetivos e os princípios da Educação Ambiental, por eles estabelecidos, seguem as mesmas orientações da Conferência de Tbilisi, realizada na Geórgia (ex-URSS) em 1977 (Unesco, 1997) e que foram corroboradas pela Conferência de 1997 em Tessalônica, na Grécia (Unesco, 1999). Essa conferência, ao examinar o papel da educação, não como uma finalidade em si mesma, mas como um instrumento-chave para se alcançar a sustentabilidade no futuro, entendeu que as determinações de Tbilisi não haviam sido totalmente exploradas, por isso, continuam válidas. Assim, o entendimento é de que as raízes de uma educação para o desenvolvimento sustentável estão firmemente implantadas na Educação Ambiental (Unesco, 1999). Esses dados indicam a força das determinações estabelecidas pela conferência de Tbilisi, uma vez que, além de ser referência para a Educação Ambiental mundial, continuam válidas há praticamente três décadas.

Como documentos de orientação à educação nacional, é claro que os PCNs orientaram também as propostas curriculares estaduais elaboradas a partir de então. Citam-se, como exemplos, o Padrão Referencial do Currículo ${ }^{3}$, elaborado pela Secretaria de Estado da Educação do Rio Grande do Sul, no período 1995/1998, e as Propostas Curriculares do Estado de Santa Catarina. Esses documentos serviram de orientação, especialmente, para as escolas públicas e, de modo geral, foram acatados também por escolas particulares e pelas Secretarias de Educação dos Municípios. No entanto, a Política Nacional de Educação Ambiental só ficou estabelecida pela Lei $\mathrm{n}^{\circ} 9.795$, de 27 de abril de 1999, regulamentada pelo Decreto ${ }^{\circ} 4.281$, de 25 de junho de 2002, segundo o qual a Educação Ambiental é instituída como obrigatória em todos os níveis de ensino e considerada componente urgente e essencial no Ensino Fundamental. Define a Educação Ambiental como "processo por meio do qual o indivíduo e a coletividade

\footnotetext{
3 "O termo Padrão Referencial do Currículo compreende um corpo básico comum de conhecimentos que pretende servir como referência para o desenvolvimento do processo de ensino e aprendizagem nas escolas dos Sistemas de Ensino do Rio Grande do Sul [...] Leva em consideração os aportes oferecidos pelos PCNs/MEC/96 e os pressupostos da Lei de Diretrizes e Bases da Educação Nacional - Lei ñ 9.394/96" (Documento Introdutório - Ensino Fundamental, p. 11).
} 
constróem valores sociais, conbecimentos, habilidades, atitudes e competências voltadas à conservação do meio ambiente, bem de uso comum do povo, essencial à sadia qualidade de vida e sua sustentabilidade" (Brasil, 1999, s/p). Preconiza, como objetivos da Educação Ambiental: o desenvolvimento de uma compreensão integrada do meio ambiente em suas múltiplas e complexas relações; o fortalecimento de uma consciência crítica sobre a problemática ambiental e social, e o incentivo à participação individual e coletiva como valor de cidadania. Incumbe as instituições educativas de promoverem a Educação Ambiental de maneira integrada aos programas educacionais que desenvolvem.

Para integrar a Educação Ambiental aos programas educativos escolares, a transversalidade e a interdisciplinaridade são apresentadas como duas características básicas. Ambas se fundamentam na crítica de uma concepção de conhecimento que toma a realidade como um conjunto de dados estáveis, sujeitos a um ato de conhecer isento e distanciado; apontam a complexidade do real e a necessidade de se considerar a teia de relações entre seus diferentes e contraditórios aspectos.

Mas, ambas também diferem entre si. Enquanto a interdisciplinaridade refere-se à abordagem epistemológica dos objetos do conhecimento e questiona a segmentação entre os diferentes campos do conhecimento, como a visão compartimentada das disciplinas, a transversalidade diz respeito, sobretudo, à dimensão didática, ou seja, à possibilidade de se estabelecer, na prática educativa, uma relação entre aprender conhecimentos sistematizados e as questões de vida real e de sua transformação (Brasil, 1998).

Sobre interdisciplinaridade, uma das maiores referências no país, a professora Ivani Fazenda, argumenta que, para se fazer interdisciplinaridade, é necessário que se tenha uma disciplina ${ }^{4}$ rigorosa. Para a autora, isso implica formar os professores na gênese de sua área de atuação e, para isso, o professor precisa saber a história, os conceitos fundamentais e as razões pelas quais abraçou esse saber. Deve refletir sobre como foi formado, que sentido tem esse conhecimento em sua vida, e estudar para poder se apropriar da evolução histórico-crítica dos conteúdos com os quais trabalha. Só assim vai poder dialogar com as outras áreas quando dialogar com a própria, pois a interdisciplinaridade nasce de uma profunda imersão na própria disciplina (Fazenda, 2005).

Decorrente das concepções de Fazenda (2005), é possível reforçar a idéia de que a temática ambiental - inserida no currículo escolar como um dos saberes a ser trabalhado -, deve ser pautada em conhecimentos e informações procedentes de fontes confiáveis e válidas, bem como na integração desses conhecimentos, pois se verifica que há uma distância muito grande entre o meio no qual o conhecimento é gerado e o meio no qual o aluno aprende esse conhecimento. Ao preparar suas aulas, o professor, normalmente, lança mão das criações didáticas e não consulta diretamente a produção científica original. Consulta livros que apresentam adaptação dos saberes ao universo escolar e que passaram por sucessivas transposições didáticas.

${ }^{4}$ Neste contexto, a autora usa a palavra disciplina como sinônimo de área de conhecimento. 
Assim, com a inserção da temática ambiental aos programas escolares do Ensino Fundamental, exigiu-se uma reflexão mais cuidadosa sobre a questão do conhecimento e da prática pedagógica. Foram necessárias, também, algumas adequações teórico-metodológicas para se alcançarem os objetivos educacionais previstos para esse grau de ensino. Se, de acordo com Fazenda (2005), há a exigência de o professor conhecer a história e os conceitos fundamentais de sua disciplina ou área de atuação, para significar e dar significado a esses conhecimentos, acredita-se que o mesmo ocorre na Educação Ambiental: é necessário contextualizar historicamente a problemática, explicitar conceitos e ir além da integração de conteúdos, ou seja, posicioná-los de forma relacional e global. Identifica-se também que, em sua base teórica, o Tema Transversal Meio Ambiente não é contraditório à visão de mundo integrada, porque está fundamentado na compreensão de que os estudantes sejam capazes de se posicionarem diante das questões que interferem na vida coletiva, superando diferenças numa intervenção responsável. Todavia, a transversalidade colocada como dimensão didática não explicita alternativas metodológicas para esse fim, o que pode, em sua implementação, levar a articulações contraditórias de suas concepções em processos educativos.

\section{Problemática ambiental}

Ao abordar a problemática ambiental, Moraes $(2001,2003)$ e Moraes e Colombi (2004) referem-se à organização humana da sociedade atual como excludente e predatória. Excludente, porque grande parte da população não tem acesso aos benefícios proporcionados pela forma de organização. Predatória, por causa da exploração imposta pelos seres humanos sobre seus semelhantes e sobre os meios naturais não humanos. $\mathrm{O}$ argumento central usado por esses autores reside na compreensão de que a maior parte dos problemas contemporâneos estão, direta ou indiretamente, relacionados às visões fragmentárias de mundo, e que estas são predominantes na população. Existe, também, a compreensão de que os problemas que as sociedades enfrentam possuem uma origem comum e podem ser explicados com base no modelo iceberg. As pontas do iceberg representam as diversas questões rotuladas de "ambientais", "sociais", "políticas", "econômicas". Uma visão mais aprofundada permite perceber que todas elas emergem de uma problemática mais ampla, a problemática relacional, provocada pela forma e intensidade das relações estabelecidas pelos seres humanos entre si e com os demais componentes do planeta. Nesse caso, as chamadas "questões ambientais" são manifestações dessa problemática.

A partir desse entendimento, Moraes (2001) argumenta sobre a natureza do conhecimento ao qual denominou conhecimento da integração. Este seria a base para a superação de visões de mundo fragmentárias e a construção de visões de mundo integradas. Ele afirma: "o conhecimento da integração vai além da integração do conhecimento, que the é necessária, mas não é suficiente" (2001, p. 4). Por outro lado, o conhecimento da integração, por si só, não garante as transformações necessárias para a superação da problemática ambiental, mas ele pode ser a base para o entendimento da mesma. Isso significa que, na Educação Escolar, não basta integrar conhecimentos entre as diferentes disciplinas; é preciso construir com base nesses conhecimentos, mas não somente deles, um conhecimento integrado do mundo. Assim sendo, uma visão de mundo integrada vai além da esfera do conhecimento, porque inclui relações dos 
seres humanos entre si e destes com o mundo. O conhecimento integrado como base de referência na construção de uma visão integrada de mundo é, portanto, centrado na idéia de que todos os humanos são partes integrantes de um mesmo ecossistema universal e estão ligados pelas mesmas leis desse sistema.

O entendimento relacional sobre os temas e conteúdos trabalhados em processos educativos escolares torna-se importante porque, mesmo diante da realidade da Educação Básica, com uma organização curricular multisseriada e multidisciplinar, esse entendimento possibilita ações educativas que visam ao conhecimento da integração, o que leva a uma reflexão sobre a fragmentação do conhecimento sobre o mundo. Valendo-se dessa compreensão, enfatiza-se a construção de estratégias pedagógicas que enfoquem o conhecimento escolar por meio das relações entre os mesmos, o que envolve não somente a percepção dessas relações, mas também a sua compreensão, gerando, assim, o ato de conhecê-las. Decorrente dessa compreensão, um tema em estudo pode ser representado didaticamente na forma de esquema relacional, uma vez que todas as coisas e todos os seres vivos possuem uma dimensão relacional. A dimensão relacional pressupõe um conceito organizador, em que nada está isolado e tudo o que existe tem uma capacidade inerente e intrínseca de se relacionar a partir de sua composição físico-química, biológica ou humana.

Em resumo, o pensamento de Moraes é de que a Abordagem Relacional possa ser uma mudança no foco da ação integradora, e a integração, o objeto do conhecimento. Essa perspectiva considera a Educação dentro da problemática ambiental e como parte integrante dela. Isso significa adotar uma posição inversa à abordagem da Educação Ambiental, que tem por lógica trazer e colocar a problemática ambiental na Educação.

\section{Visões de mundo}

A constatação de que muitas pessoas possuem uma visão fragmentária da realidade e de que a Educação deve favorecer o desenvolvimento de habilidades intelectuais que permitam perceber relações entre os fatos, suas causas e conseqüências, já foram explicitadas e reforçadas por autores que escrevem sobre o tema, como: Moraes (2001, 2003); Moraes e Colombi (2004); Cobern (1991, 1996); Aerts et al. (1994) e Olsen (1992). Nessa perspectiva, a educação é fundamental, pois faz a mediação entre as visões de mundo e a organização humana. Num processo dinâmico e recursivo, a educação reproduz ou modifica as visões de mundo com base nas visões de mundo sobre a qual foi concebida. Isso significa que as experiências vivenciadas pelo ser humano, tanto no plano individual como coletivo, quando compatíveis com as visões de mundo que tem interiorizado, são prontamente assimiladas. Quando essas experiências não são compatíveis com a visão de mundo do sujeito, são rejeitadas ou, então, a sua visão de mundo terá de ser adequada ou modificada. Esse aspecto é importante uma vez que a visão de mundo que o sujeito tem, de certa forma, orienta suas ações e condutas, independente de estar consciente ou não sobre as mesmas. Assim, a visão de mundo pode ser pensada e entendida como uma macroestrutura epistemológica (conjunto de pressuposições) que forma a base para a visão da realidade ou natureza (Cobern, 1991 ). Por compreender um conjunto de valores, conceitos e crenças, as visões de mundo dão significado à realidade em que se vive e em que se produz o conhecimento. 
Construir uma visão de mundo implica desenvolver visões que consideram os aspectos da experiência humana, sejam eles teóricos ou práticos. Os aspectos da experiência prática lidam com as coisas do mundo concreto, como a interpretação da história e do conhecimento científico sobre o mundo (Aerts et al., 1994). Para esses autores, as visões de mundo são modelos de referência que permitem não apenas estabelecer relações, mas também perceber a interconexão dos problemas quanto às relações que se estabelecem entre as diferentes nações, culturas e economias. A idéia de modelo e de globalidade, presente em visões de mundo integradas, construídas com o propósito de superar o processo de fragmentação predominante na população, é expressa na seguinte citação: "as visões de mundo globais são como mapas geográficos, que nos ajudam a encontrar nosso caminho e agir com coerência neste mundo" (p.3).

Moraes $(2001,2003)$ aborda a Educação e a problemática ambiental com base nas visões de mundo, uma vez que o conceito de visão de mundo é utilizado como um instrumento útil na compreensão da realidade e dos padrões de comportamento. Ao explicar sua compreensão sobre o tema, ele reafirma o pensamento de Cobern $(1991,1996)$, de que as visões de mundo são individuais, culturalmente dependentes e socialmente construídas. Estão ligadas a uma determinada época e a civilizações específicas, de maneira que é possível concebê-las numa perspectiva histórica e de mudança. As mudanças pressupõem ruptura e/ou reorganização de alguma forma de conhecimento para que novas visões de mundo sejam concebidas. Estas acontecem a partir das experiências vivenciadas, possibilitam novas compreensões e, por decorrência, o avanço do conhecimento.

Argumenta-se, então, que as visões de mundo decorrem da maneira como se conhece, observa-se, aprende-se e se interpreta aquilo que está no entorno. Por essas razões, as visões de mundo se constituem num quadro epistêmico mais amplo e abrangente, que favorece a compreensão da natureza humana, da organização social e do funcionamento das próprias leis da natureza, permitindo compreender a realidade com base numa racionalidade. Ser racional, para Cobern (1991), significa pensar e atuar com razão, ou seja, ter uma explicação ou uma justificativa para o pensamento e a ação. Nesse sentido, as visões de mundo estão ligadas à definição do próprio eu da pessoa (self). Determinam as fronteiras entre o que é meu e aquilo que não é meu, incluindo as relações que o indivíduo estabelece com o ambiente humano e não humano. Por isso, mesmo sendo subjetivas, as visões de mundo pressupõem normas e valores culturalmente definidos. Assim, procurar identificar os aspectos inerentes às visões de mundo predominantes na atual sociedade brasileira é fundamental para compreender, por exemplo, as orientações teóricas das políticas educacionais vigentes e avaliar a repercussão dessas nos processos educativos.

\section{Construção e componentes das Visões de Mundo}

A idéia de que a coerência e fidelidade à experiência são propriedades fundamentais na construção de uma visão de mundo é reforçada por Aerts et al. (1994). No entanto, uma visão de mundo deve permitir compreender tantos aspectos quantos possíveis de forma que, não apenas a experiência científica, mas também a sensibilidade, a estética e a ética terão profunda influência na construção de uma visão de mundo. Justifica-se esse argumento pelo fato de que, numa determinada cultura, as artes, as letras, os costumes, bem como os códigos de 
conduta estão inter-relacionados. A práxis política deve ser incluída nesses aspectos, reafirmando a idéia de que elementos de ordem ideológica também fazem parte das visões de mundo.

Como se observa, as visões de mundo estão ligadas a uma civilização específica e a uma determinada época e, mesmo sendo individuais, são construídas coletivamente. Outros aspectos que devem ser considerados na construção de uma visão de mundo são a ciência e as modernas tecnologias, especialmente as das comunicações, que viabilizam a interação entre as culturas e a aproximação dos povos. Como decorrência dessa aproximação, os projetos de vida pessoal são cada vez mais influenciados e determinados pela rede de relações que as pessoas mantêm com diferentes grupos. Dessa forma, a humanidade só pode ser vista como parte de um todo maior, o que aumenta a responsabilidade individual em interagir para cuidar de questões coletivas e que dizem respeito a toda a humanidade. Assim, na construção de uma visão de mundo contemporânea, os elementos de visão de mundo anteriores e seus aspectos de intuição, emoção e imaginação devem ser considerados, porque são referências afetivas e culturais das pessoas.

Aerts et al. (1994) têm um enfoque pós-moderno sobre as visões de mundo. Esses autores reconhecem as limitações da razão e sua historicidade. Argumentam que a razão crítica e o entusiasmo emocional não precisam se excluir mutuamente e podem contribuir para a construção de visões de mundo. Apresentam, então, sete pontos básicos que devem ser considerados em toda visão de mundo. Na verdade, esses pontos são grandes questionamentos que articulam diferentes subtarefas interligadas e necessárias para formar um todo coerente. No entanto, a construção da visão de mundo não pode ser vista como uma projeção arbitrária. Pode, sim, ser comparada ao trabalho dos cartógrafos da Antigüidade e da Idade Média, que construíam mapas do mundo usando informações recebidas de navegadores, mercadores e exploradores. Essas informações, com freqüência, eram incompletas, imprecisas, contraditórias e, até mesmo, inventadas. Na construção desses mapas, gradualmente, os cartógrafos ajustavam e formatavam uma imagem coerente introduzindo novos dados. $\mathrm{Na}$ atualidade, com o acesso às novas tecnologias digitais e de comunicação, para se construir uma visão coerente com o todo, é necessário 'filtrar' as informações recebidas diariamente e ter habilidade intelectual para relacionar fatos e dados.

Quanto aos componentes das visões de mundo, esses são descritos por Aerts et al. (1994) em sete categorias ou pontos de questionamento interligados e aos quais estão relacionadas subtarefas. Procurou-se entender a idéia central de cada questionamento e a(s) respectiva(s) subtarefa(s) que são descritas a seguir.

O primeiro ponto apresentado pelos autores refere-se à natureza do mundo, sua estrutura e funcionamento. Para esse fim, utilizam-se os conceitos de mundo, natureza e universo de forma mais geral possível. Entende-se que a descrição do mundo, ou seja, como ele é estruturado e como funciona, já pressupõe a escolha de um modelo que exige a representação da realidade por meio de um sistema simbólico de conceitos. Descrever o mundo envolve a seleção de diferenças, e perceber diferenças depende do observador, da relação que estabelece com os instrumentos de observação e da interpretação que faz da realidade observada.

Como segundo ponto, os autores apresentam o poder explicativo da visão de mundo. Argumentam que não basta conhecer os fatos, é preciso entendê-los, percebê-los e explicá-los. Explicar significa tornar compreensível, esclarecer, analisar e, até mesmo, justificar um fato que poderá ser um problema ambiental. Nessa perspectiva, ao entender as razões que expli- 
cam um determinado fato ou fenômeno, é possível formular conexões significativas, por exemplo, a respeito de sua origem. A explicação se dá sempre com base em diferentes modelos ou paradigmas do conhecimento. A análise de um fato, tomando-se por base diferentes enfoques, é fundamental na construção de uma visão de mundo integrada. Assim, nos processos educativos, não basta dizer que existem problemas ambientais causados, por exemplo, pelo lixo, que é um dos temas trabalhados, com freqüência, por escolas brasileiras. Nesse caso, é preciso indagar as causas que levam a esses problemas, desde o ponto de vista da produção desses bens de consumo que, muitas vezes, envolve relações de trabalho contraditórias ou conflituosas. Deve-se considerar e discutir, também, o acesso a esses bens, o incentivo ao consumo pela propaganda e, finalmente, a falta de um destino apropriado aos resíduos sólidos produzidos. Nessa abordagem, o problema lixo é colocado e explicado numa rede de relações.

O terceiro ponto mencionado por Aerts et al. (1994) refere-se à avaliação. A avaliação parte da premissa da não neutralidade do mundo e considera as condutas humanas frente à realidade, como opcionais e de acordo com a relevância dos fatos. Assim, uma visão de mundo contém os meios para se compreender e avaliar uma realidade, em diferentes culturas, além de expressar os valores e elementos inerentes à existência humana. A avaliação permite identificar diferentes visões de mundo, na medida em que os elementos da existência humana não são iguais, e sim variados.

O quarto ponto procura esclarecer o lugar que a humanidade ocupa no mundo e posicionar as relações mais significantes. Nesse sentido, aborda questões referentes ao futuro da humanidade a curto, médio e longo prazo, e ao futuro da Terra, considerando os problemas ecológicos do meio ambiente. Inclui também a maneira de lidar com a finitude da vida e a transcendência. Esses aspectos são comumente ligados a questões religiosas e culturais, mas são constituintes da visão de mundo predominante de um povo.

O quinto ponto refere-se à subjetividade como elemento a ser considerado no processo de construção de um 'modelo' da realidade que se constitui na visão de mundo. Isso significa dizer que o conhecimento, as crenças e os valores são subjetivos e limitados a uma cultura historicamente determinada. No entanto, "uma visão de mundo não é mera reflexão sobre a realidade objetiva e nem uma construção puramente subjetiva. Hoje, o universo não pode mais ser examinado sem levar em conta aquele que observa este universo" (Aerts et al., 1994, p. 14). Com essa afirmação, os autores acentuam a importância do pesquisador e de sua visão de mundo na percepção objetiva da realidade.

O sexto ponto orienta a busca de um modelo de ação integrada e interdisciplinar, enquanto o sétimo ponto refere-se aos fragmentos de visões de mundo como ponto de partida para a construção de visões de mundo integrada. Os autores argumentam que se devem evitar esforços direcionados à construção de uma visão de mundo única e procurar diferentes visões de mundo coerentemente conectadas com espaços para a pluralidade.

Considera-se que os sete pontos descritos por Aerts et al. (1994) como componentes das visões de mundo são importantes nos processos educativos em geral. De maneira particular, os dois últimos pontos têm importância ainda maior nos processos educativos voltados à Educação Ambiental. A busca de um modelo de ação integrada, de que trata o sexto ponto, contém, em essência, a dimensão didática e metodológica da Educação Ambiental, orientada para ser desenvolvida de forma sistemática, contínua e transversa nos processos educativos escolares. Já a interdisciplinaridade e a formação de uma visão de mundo integrada remetem a 
Boer, N.; Moraes, E. C.

fundamentos epistemológicos que, a princípio, devem orientar não apenas o corpo teórico de conhecimentos trabalhados pela educação escolar, mas também as práticas docentes dos professores.

\section{Considerações finais}

Um referencial construído a partir da visão de mundo integrada e da abordagem relacional pode nos auxiliar a compreender os processos educativos construídos com base nas orientações das políticas educacionais, tanto nos seus pontos de convergência com este referencial, como em seus pontos discordantes. Identifica-se, como principal ponto de divergência entre as políticas de Educação Ambiental e este referencial, o fato de que, no primeiro caso, a problemática ambiental é conduzida para o seio da Educação e, no segundo, a Educação é concebida como parte da problemática ambiental, o que representa uma inversão de eixo epistemológico. Possivelmente, por essas razões, as práticas educativas desenvolvidas pela Educação Ambiental não tenham alcançado a eficácia esperada quando baseadas em visões fragmentárias de mundo e em ações pontuais. Assim, os processos educativos que queiram contribuir para a percepção, compreensão e conhecimento das relações existentes numa determinada realidade devem ser construídos com base em visões de mundo integradas. Isso significa uma mudança no foco da ação integradora e na integração do objeto do conhecimento. Nessa perspectiva, acredita-se que a visão integrada de mundo e a dimensão relacional podem contribuir para uma mudança na atual abordagem da Educação Ambiental.

\section{Referências}

AERTS, D.; APOSTEL, L.; MOOR, B.; HELLEMANS, S.; MAEX, E.; VAN BELLE, H.; VAN DER VEKEN, J. Worldviews: from fragmentation to integration. VUB Press: Brussels, 1994.

ARELARO, L. R. G. Resistência e submissão: a reforma educacional na década de 1990. In: KRAWCZYK, N.; CAMPOS, M. M.; HADDAD, S. (Orgs.). O cenário educacional Latinoamericano no limiar do século XXI: reformas em debate. Campinas: Autores Associados, 2000. p. 95-116. (Coleção Educação Contemporânea). 
Políticas educacionais, visões de mundo e...

BONAMINO, A; MARTÍNEZ, S. A. Diretrizes e parâmetros curriculares nacionais para o ensino fundamental: a participação das instâncias políticas do estado. Educação \& Sociedade, v. 23, n. 80 , p. $371-388,2002$.

BRASIL. Constituição. Brasília: Senado Federal, 1988. . Secretaria de Educação Fundamental. Parâmetros curriculares nacionais: terceiro e quarto ciclos: Temas transversais. Brasília: MEC/SEF, 1998.

. Congresso Federal. Lei n 9.795 - de 27 de abril de 1999. Dispõe sobre a Educação

Ambiental. Institui a política nacional de educação ambiental e dá outras providências.

. Ministério da Educação e Desporto. Plano Nacional de Educação para Todos: 1993 - 2003. Brasília: MEC, 1994.

COBERN, W. W. World view theory and science education research. The National Association for Research in Science Teaching ( NARST), Monograph. Number 3. Arizona, USA, 1991.

Worldview theory and conceptual change in science education. Science Education. v. 5 , n. 80 , p. $579-610,1996$.

CARVALHO, I. C. M. Educação ambiental: a formação do sujeito ecológico. São Paulo: Cortez, 2004.

FAZENDA, I. Interdisciplinaridade exige acima de tudo disciplina. ABC Educatio. São Paulo. Ano 6, n. 43, mar. 2005, p. 5-9. Entrevista.

MORAES, E. C. Ações pedagógicas relacionais. Florianópolis, 2001. (mimeogr.).

- Abordagem relacional: uma estratégia pedagógica para a educação científica na construção de um conhecimento integrado. In: ENCONTRO NACIONAL DE PESQUISA EM EDUCAÇÃO EM CIÊNCIAS, 4., 2003. Bauru. Anais... Bauru: ABRAPEC, 2003. CDROM.

MORAES, E. C.; COLOMBI, A. N. K. Sustentabilidade e educação biológica: Uma perspectiva relacional. In: CONFERÊNCIA INTERNACIONAL DE EDUCAÇÃO BIOLÓGICA, DESENVOLVIMENTO SUSTENTÁVEL, ÉTICA E CIDADANIA, 2004. Rio de Janeiro. Anais ... Rio de Janeiro: Fiocruz, 2004. (no prelo).

OLSEN, M. E; LODWICK. D. G; DUNLAP, R. E. Viewing the world ecologically. Boulder: Westview Press, 1992. 
Boer, N.; Moraes, E. C.

UNESCO. Educação ambiental: as grandes orientações da conferência de Tbilisi. Brasília: IBAMA, 1997.

Educação para um futuro sustentável: uma visão transdisciplinar para ações compartilhadas. Brasília: IBAMA, 1999.

Artigo recebido em fevereiro de 2006 e aceito em agosto de 2006 